\title{
Characteristics of non-crystalline thin oxide films formed on aluminum by plasma electrolytic oxidation
}

\author{
A. Anawati, ${ }^{1 *}$ H. Labibah ${ }^{1}$ and S. Purwanto ${ }^{2}$ \\ ${ }^{1}$ Departemen Fisika, Fakultas Matematika dan Ilmu Pengetahuan Alam, Universitas \\ Indonesia, Depok 16424, Indonesia \\ ${ }^{2}$ Fakultas Ketenagalistrikan dan Energi Terbarukan, Institut Teknologi PLN, Cengkareng, \\ Jakarta Barat 11750, Indonesia \\ *E-mail: anawati@sci.ui.ac.id
}

\begin{abstract}
Anti-corrosion oxide films were developed on $\mathrm{Al}$ substrate by plasma electrolytic oxidation (PEO) in a mix of phosphate, carbonate, silicate, and hydroxide electrolyte. The role of silicate and hydroxide in the PEO process were investigated. PEO was conducted under a DC mode at $400 \mathrm{~A} \cdot \mathrm{m}^{-2}$ at $283 \mathrm{~K}$ for $120 \mathrm{~s}$. The resulting films were free of cracks with thicknesses of $\sim 2-$ $3 \mu \mathrm{m}$ composed of amorphous aluminum oxide, as confirmed by XRD and EDS analyses. Variation of anion concentration did not vary the incorporation of the anion species in the oxide film significantly. The films enhanced the mechanical hardness $\sim 20 \mathrm{HV}$. Substantial improvement in corrosion resistance up to two orders of magnitude was demonstrated by the polarization curves and electrochemical impedance spectra. Surface investigation using a scanning electron microscope revealed a pore population reduction with increasing silicate volume in the electrolyte. Synergism effect of silicate and hydroxide in the electrolyte containing a higher fraction of both anions induced the generation of soft sparking, which produced a more protective inner layer. The electrolyte composition is beneficial in obtaining thin oxide films with superior corrosion resistance.
\end{abstract}

Keywords: aluminum, plasma, microstructure, thin film, hardness, impedance, corrosion.

Received: May 4, 2021. Published: June 15, 2021

doi: $\underline{10.17675 / 2305-6894-2020-10-2-20}$

\section{Introduction}

Plasma electrolytic oxidation (PEO) is a surface modification to create a protective ceramiclike oxide layer on a metal surface. The method attracted significant attention due to its simplicity and environmentally friendly process. Plasma is generated by applying a $\mathrm{DC} / \mathrm{AC} /$ modified current to a metal substrate submerged in an aqueous electrolyte. The process involved complex reactions, namely electrochemical, metallurgical, and thermochemical reactions [1]. The resulting oxide layer provides improvement to the mechanical properties and the corrosion resistance of the metal substrate [2,3]. The method can be applied to various valve metals, including $\mathrm{Al}, \mathrm{Mg}, \mathrm{Ti}, \mathrm{Zr}, \mathrm{W}$, etc.

The PEO layer exhibits lava-like morphology with a pore at the center. The porosity is beneficial for some applications as it opens the possibility to fill the pore with other 
substances to obtain specific characteristics such as magnetic [4], bioactive [5], and superconducting properties [6]. However, the pores are detrimental to corrosion properties. The morphology of the PEO coating was controlled by plasma discharge characteristics such as size and intensity. The type of plasma involved in the PEO includes micro-spark, arc, long-lived arc, and soft spark [7]. The discharge characteristics were determined by the applied electric current, electrolyte condition, and substrate composition. The plasma generated by the alternating current (AC) is more complicated than the direct current (DC) mode. The electrolyte used for PEO is an alkaline solution, namely silicate-, hydroxide-, aluminate-, carbonate-, borate-, and phosphate-based electrolyte. The ionic species from the PEO bath was detected in the oxide layer [8-10]. Therefore, bath composition played a significant role in the composition and the microstructure and corrosion resistance of the coating. Most of the PEO on Al substrate used silicate-based electrolyte [11-14]. There is a lack of reports on the use of mixed electrolytes containing phosphate and carbonate electrolyte. Phosphate coating is effectively used to protect engineering surfaces from corrosion and wear [15].

In this work, the PEO was conducted on an $\mathrm{Al}$ substrate in a mixed electrolyte containing primary phosphate and carbonate with a variation of volume fraction silicate and hydroxide. The PEO was terminated at 2 min to obtain a thin oxide layer. The resulting coating microstructure was investigated using FE-SEM. The chemical composition and crystalline phase were analyzed by EDS and XRD, respectively. Electrochemical tests were conducted to study the corrosion behavior.

\section{Materials and Method}

\section{Materials}

A commercially pure aluminum $(\mathrm{CP}-\mathrm{Al})$ rolled plate with the dimension of $15 \mathrm{~mm} \times$ $15 \mathrm{~mm} \times 1 \mathrm{~mm}$ was used as a specimen. The plate was washed in acetone and ethanol for 3 min each in an ultrasonic bath.

\section{Plasma electrolytic oxidation}

The PEO process was carried out in an alkaline electrolyte denoted as electrolytes $\mathrm{A}, \mathrm{B}$, and C. Individual electrolytes of $\mathrm{Na}_{3} \mathrm{PO}_{4}, \mathrm{NaOH}, \mathrm{Na}_{2} \mathrm{SiO}_{3}$, and $\mathrm{Na}_{2} \mathrm{CO}_{3}$ with a concentration of $0.5 \mathrm{M}$ were prepared. The electrolytes were then mixed following the volume fraction listed in Table 1. The electrolyte conductivity was measured using TOA CM-11P conductivity meter.

The PEO was performed using two electrodes configuration: the specimen was placed as an anode, and two carbon rods were set as a cathode. A DC power supply (GW Instek) was used for supplying a constant current density of $400 \mathrm{~A} \cdot \mathrm{m}^{-2}$ for $120 \mathrm{~s}$. The voltage output was recorded using a multimeter data logger (Rigol). The electrolyte was continuously stirred at $300 \mathrm{rpm}$. The bath temperature was maintained at $283 \mathrm{~K}$. The specimen was then washed thoroughly using de-ionized water (DI) water and then dried. 
Table 1. Ratio of mixed electrolytes.

\begin{tabular}{ccccc}
\hline \multirow{2}{*}{ Electrolyte } & \multicolumn{5}{c}{ Ratio } \\
\cline { 2 - 5 } & $\mathrm{Na3P}_{4}$ & $\mathbf{N a O H}$ & $\mathbf{N a 2 S i O}_{3}$ & $\mathrm{Na}_{2} \mathrm{CO}_{3}$ \\
\hline $\mathrm{A}$ & 6 & 2 & 1 & 1 \\
$\mathrm{~B}$ & 6 & 1 & 2 & 1 \\
$\mathrm{C}$ & 5 & 2 & 2 & 1 \\
\hline
\end{tabular}

\section{Characterization}

The surface morphology and cross-sectional views of the oxide films were investigated using a field-emission scanning electron microscope (FE-SEM, Phenom Pharos). The instrument was attached to the energy dispersive spectroscopy (EDS) for analyzing the elemental composition. The mechanical properties of the anodic film were measured by Vickers hardness test using a micro-indentation machine (MicroMet ${ }^{\circledR} 5100$ Series) with a load of 25 gf. The test followed ASTM E384.

\section{Electrochemical test}

The corrosion behavior of the coated specimens was studied by measuring open circuit potential (OCP) and potentiodynamic polarization in $3.5 \mathrm{wt} \% \mathrm{NaCl}$ solution at $30^{\circ} \mathrm{C}$ using Corrtest CS310 potentiostat. The electrochemical cell consisted of three electrodes with the specimen as a working electrode, a Pt sheet as a counter electrode, and silver/silver chloride $(\mathrm{Ag} / \mathrm{AgCl})$ as a reference electrode. The corrosion potential and corrosion current density were analyzed by using Tafel extrapolation. Electrochemical impedance spectroscopy (EIS) measurements were performed to investigate the impedance spectra of the oxide films as a function of frequency. The frequency ranged from $10^{-2}$ to $10^{5} \mathrm{~Hz}$.

\section{Results and Discussion}

\section{Formation of Oxide Film}

The growth mechanism of the thin oxide films on the Al substrate was studied from the voltage-time curve. Figure 1 displays the voltage-time plot during $120 \mathrm{~s}$ formation of the oxide films in the electrolytes $\mathrm{A}, \mathrm{B}$, and $\mathrm{C}$. At the initial electrolysis time, the voltage increased rapidly following a linear line with a gradient of 4.8, 6.7, and 7.1 V/s for electrolyte $\mathrm{A}, \mathrm{B}$, and C. According to Ohm's law, at a constant current, the voltage is proportional to the resistance. The rapid increase of surface resistance indicated the formation of a barrier layer covering the electrode surface. Breakdown of the barrier layer occurred at approximately $150 \mathrm{~V}$, after which the slope decreased. Plasma was generated on the surface in the form of fine white micro-sparks. The number of micro-sparks increased with time. Hence the voltage tended to be stabilized. 
The electrolyte conductivity played a significant role in the excitation of spark discharge. Table 2 lists the electrolyte conductivity. The conductivity increased slightly with the addition of silicate individually or together with hydroxide. The presence of hydroxide in the electrolyte had a less significant effect on the conductivity than silicate. The B and C curves in Figure 1 overlapped and were higher than the A curve up to $65 \mathrm{~s}$. In electrolyte A, the film was grown by rapid sparking, and the spark grew more prominent with time. Meanwhile, a travel arc in yellow color was generated in electrolyte B and C following the rapid spark. The electrolyte with higher ionic conductivity stimulated the electric field strength built at the electrode surface, achieving the critical voltage for the travel arc.

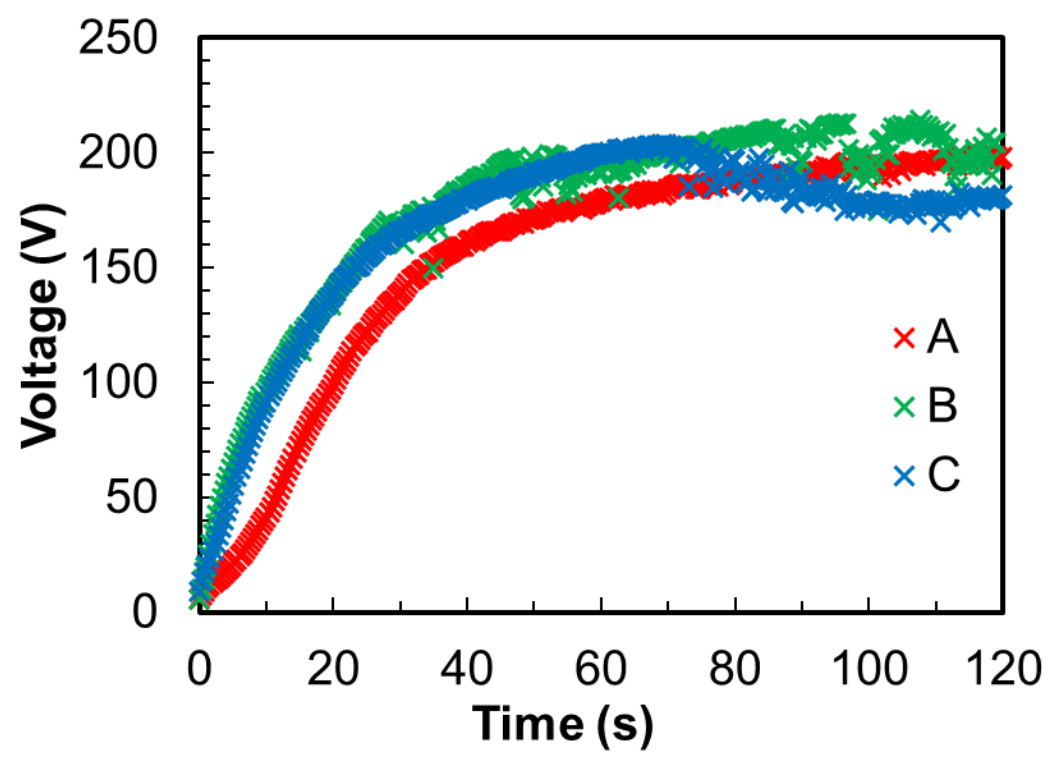

Figure 1. Voltage-time plot during plasma electrolysis in electrolytes A, B, and C.

Table 2. Electrolyte conductivity.

\begin{tabular}{cccc}
\hline Electrolyte & A & B & C \\
\hline Conductivity, $\mathbf{m S} / \mathbf{c m}$ & 139 & 145 & 141 \\
\hline
\end{tabular}

The higher content of silicate and hydroxide ions in electrolyte $\mathrm{C}$ accelerated the generation of soft sparking at $65 \mathrm{~s}$. The soft sparking regime was indicated by the reduction in the voltage output. The travel arc was replaced by a low-intensity spark at the soft sparking regime. The terminal voltage for A and B curves was similar at $204 \mathrm{~V}$ while at a lower voltage of $179 \mathrm{~V}$ for electrolyte $\mathrm{C}$.

The type of discharge generated during electrolysis affected the resulting film morphology. Figure 2 shows the FE-SEM images of the resulting oxide film in both planeand cross-sectional views. The surface view in Figures $2 \mathrm{a}-2 \mathrm{c}$ revealed the uniformly grown oxide films following the substrate shape, such as rolling lines (RL). The films were free of cracks. Cracks have been the main issue in the film resulting from PEO. Decreasing the film 
thickness is proved to be beneficial in reducing cracks. The films exhibited porous morphology in which the pore was distributed randomly. The pore was associated with the discharge tunnel. The micro-arc created fine pore size while arc discharge produced larger pore and induced local oxide thickening. The arc moved following the rolling lines as revealed from the pore path. The soft sparking regime in electrolyte $\mathrm{C}$ yielded to finer pore size, as shown in Figure 2c. Similar to the earlier report [16], the soft sparking produced the more uniform and denser film.

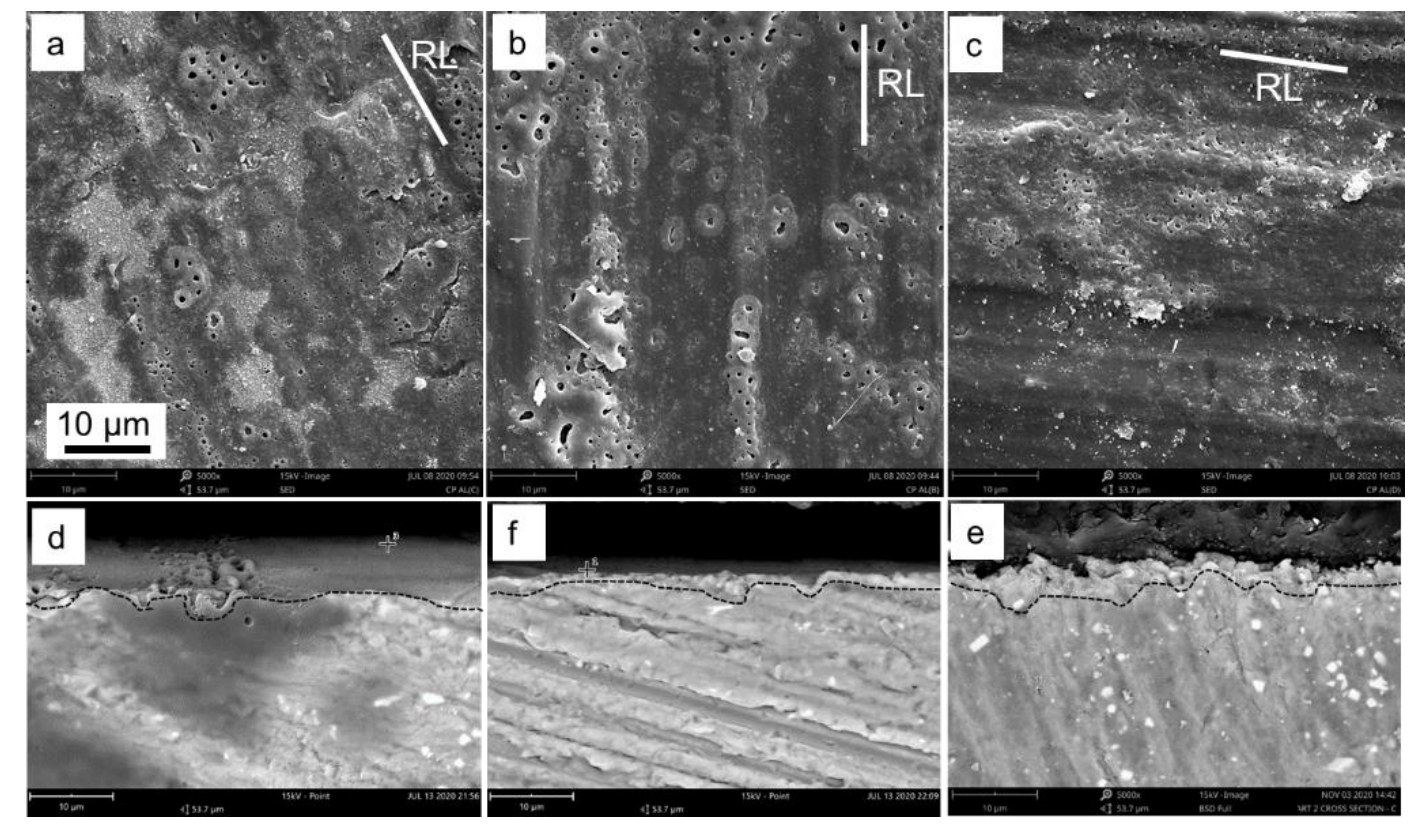

Figure 2. FE-SEM images of the oxide film in (a)-(c) plane- and (d)-(f) cross-sectional views. RL stands for rolling line. The scale bar in image a) applied to all images.

Confirming the surface observation, the cross-sectional images in Figures $2 \mathrm{~d}-2 \mathrm{f}$ show thin oxide films in the range $2-3 \mu \mathrm{m}$ enclosed the substrate surfaces. The film structure indicated both inward and outward growth of the oxide during electrolysis. The zigzag structure of the film-substrate interface was evident of the inward growth, while the porous outer layer suggested the outward growth of the oxide. Few local oxide thickenings created a deeper crater in the films. The number of craters increased significantly in the B film, yielding to the rougher metal interface.

\section{Chemical composition}

Figure 3 displays the elemental composition and the XRD pattern of the oxide films. The films were composed of aluminum oxide, as indicated by the high concentration of $\mathrm{Al}$ and $\mathrm{O}$ in Figure 3a. The PEO of aluminum produced primarily aluminum oxide [17-19]. The elements from the electrolyte, namely $\mathrm{C}, \mathrm{P}, \mathrm{Si}$, and $\mathrm{Na}$, were detected in the oxide at a low concentration. Silicate ions were more reactive as it incorporated in the film at a slightly higher concentration than phosphate ions. The $\mathrm{C}$ concentration increased significantly, 
which counterbalanced the Si content in the film formed in electrolyte $\mathrm{C}$. The $\mathrm{C}$ signal was mainly originated from the resin used as a holder.

The heat produced by the plasma was sufficiently high to melt the surrounding metal substrate and boil the local electrolyte. It was believed that the oxide phase was developed inside the gas-vapor envelope, which then condensed into a liquid [20]. The chemical reaction between the metal substance and the electrolyte species occurred inside the gasvapor envelope [21].
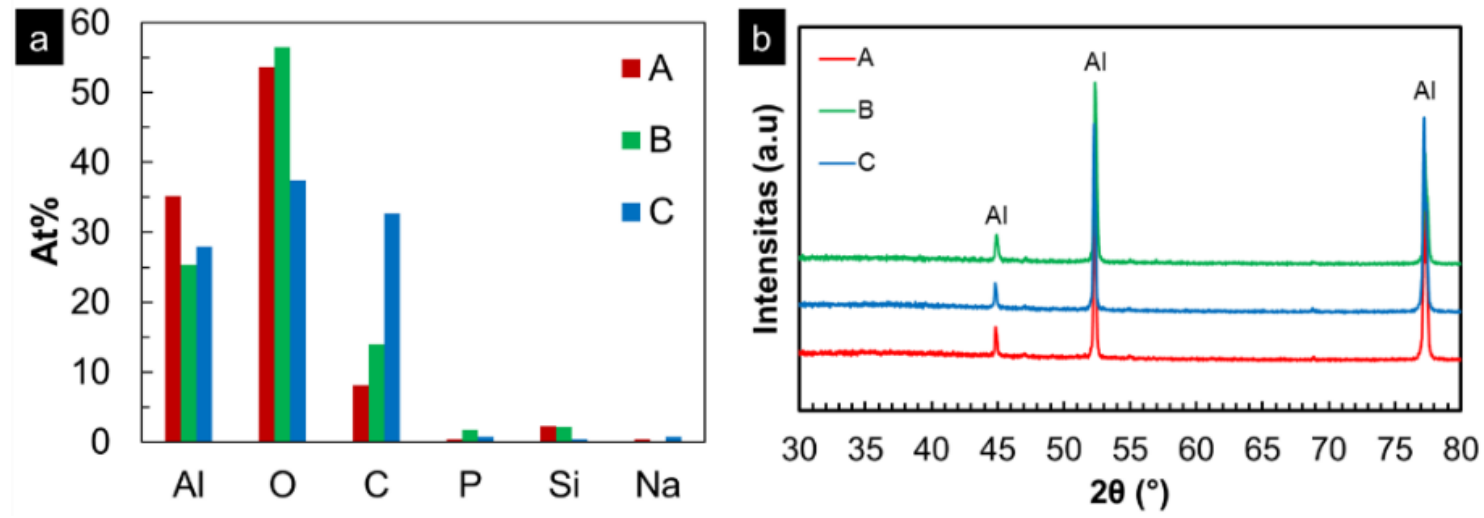

Figure 3. a) EDS elemental concentration and b) XRD pattern of the oxide films formed in electrolytes A, B, and C.

Figure $3 \mathrm{~b}$ displays the XRD pattern of the coated specimens. The crystalline oxide phase was not detected as no peaks other than $\mathrm{Al}$ appeared in the pattern. The absence of a crystalline peak indicated that the oxide film was composed of the amorphous phase only. The short processing time of 2 min limited the nucleation of crystalline oxide.

\section{Mechanical hardness}

The presence of an oxide layer resulted from plasma electrolysis affected the specimen hardness. Figure 4 shows the hardness of the coated specimens in comparison with the substrate. The $\mathrm{CP}-\mathrm{Al}$ substrate exhibited a hardness of $45 \mathrm{HV}$. The coated specimens showed higher hardness in the range $61.2-68.8 \mathrm{HV}$. The size and number of pores in the oxide layer varied the hardness slightly. The smaller number of pores yielded a higher hardness value. The hardness value of the coated specimen was significantly low as compared to the reference [22] that reported enhancement of hardness to several orders of magnitude with the crystalline PEO film with a thickness in the range of ten to a hundred micron. The relatively thin oxide developed in this work contributed to the small gain in hardness. Nevertheless, the slight increase of hardness is beneficial in keeping the surface flexibility during deformation. 


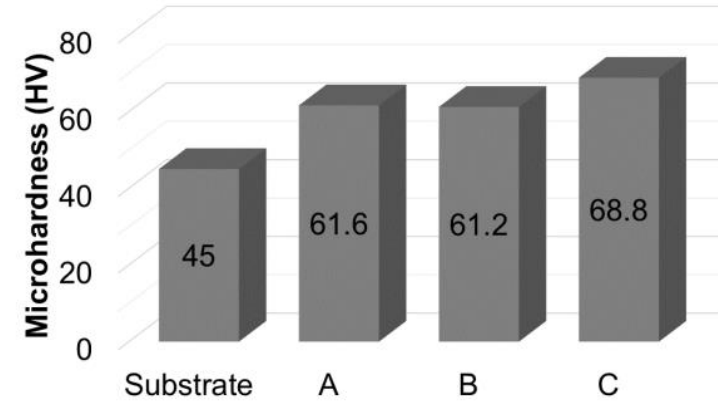

Figure 4. Microhardness of the coated specimens in electrolytes A, B, and C, and the substrate.

\section{Electrochemical corrosion behavior}

Figure 5 displays the open circuit potentials (OCP) as a function of time and the potentiodynamic polarization curves of the specimens. Despite the small ripple, all the specimens demonstrated a relatively stable free corrosion potential with time, as shown in Figure 6a. The OCP curves of the coated specimens were overlapped at approximately -0.63 $V_{\mathrm{Ag} / \mathrm{AgCl}}$, which was $70 \mathrm{mV}$ nobler than the substrate. The result was consistent with the polarization curves shown in Figure 5b. The curves of the coated specimens shifted towards higher potential and to lower current density relative to the substrate. The ennoblement of corrosion potential and reduction of corrosion current density demonstrated an improvement of corrosion resistance. The corrosion potential and corrosion current density obtained from the polarization curve were tabulated in Table 3. The corrosion potential of A specimen was $70 \mathrm{mV}$ higher than the substrate. Further ennoblement was obtained in the B and C specimens resulting from $\mathrm{PEO}$ in higher silicate containing solution. Although the corrosion potential of $\mathrm{B}$ and $\mathrm{C}$ specimens were similar, the $\mathrm{C}$ specimen had an order magnitude lower current density than the B specimen. The soft sparking events in electrolyte $\mathrm{C}$ produced a more protective oxide layer.
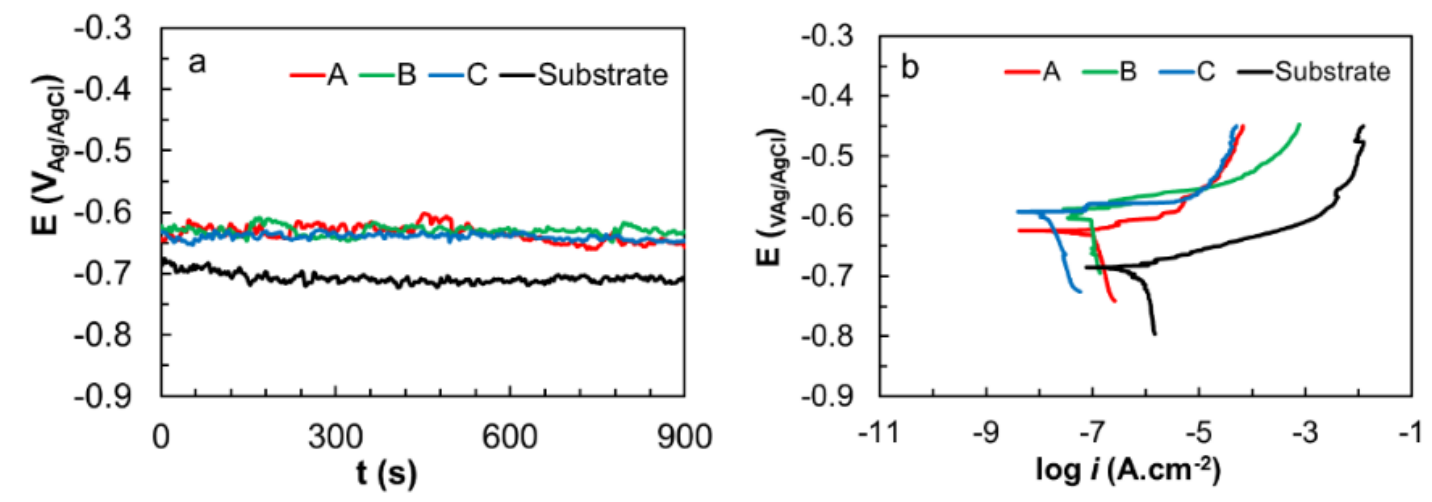

Figure 5. Open circuit potential and potentiodynamic polarization of the substrate and the coated specimens in electrolyte A, B, and C.

The resistivity of the oxide films as a function of frequency was analyzed by EIS. Figure 6 shows the EIS spectra in Nyquist and Bode diagrams. The data were fitted following 
the Randles circuit shown in Figure 6d. The fitting parameters are listed in Table 4. The equivalent circuit consisted of $R_{\mathrm{s}}$, which represented the solution resistance and two constant phase elements (CPE), each in parallel with a resistor that modeled the surface layers. The exponent $n$ for the two CPE was larger than 0.8, confirming the capacitive behavior of the two layers. An inductor $(L)$ is added to the circuit model of the substrate to represent the corrosion activity.

Table 3. Corrosion potential $\left(E_{\text {corr }}\right)$ and corrosion current density $\left(i_{\text {corr }}\right)$ from the polarization curves in Figure 5b.

\begin{tabular}{ccc}
\hline Specimen & $\boldsymbol{E}_{\mathbf{c o r r}}, \mathbf{V}$ & $\boldsymbol{i}_{\mathbf{c o r r}}, \mathbf{A} \cdot \mathbf{c m}^{-\mathbf{2}}$ \\
\hline Substrate & -0.69 & $1.97 \cdot 10^{-6}$ \\
Coated-A & -0.62 & $4.81 \cdot 10^{-7}$ \\
Coated-B & -0.59 & $4.3 \cdot 10^{-7}$ \\
Coated-C & -0.59 & $6.45 \cdot 10^{-8}$ \\
\hline
\end{tabular}

The Nyquist diagram of the coated specimens consisted of two semicircles corresponding to two time-constants. The first loop in the high-frequency ranges appeared to result from the functional layer, and the second loop in the medium frequency ranges, which was smaller, was related to the inner layer. The impedance spectra (Figures 6a and $6 \mathrm{~b})$ of the coated specimens were two orders magnitude larger, indicating 100x higher corrosion resistance than that of the substrate. The coating effectively suppressed the corrosion initiation on the specimen, as illustrated by the absence of an inductive loop in the Nyquist plots of the coated specimens.
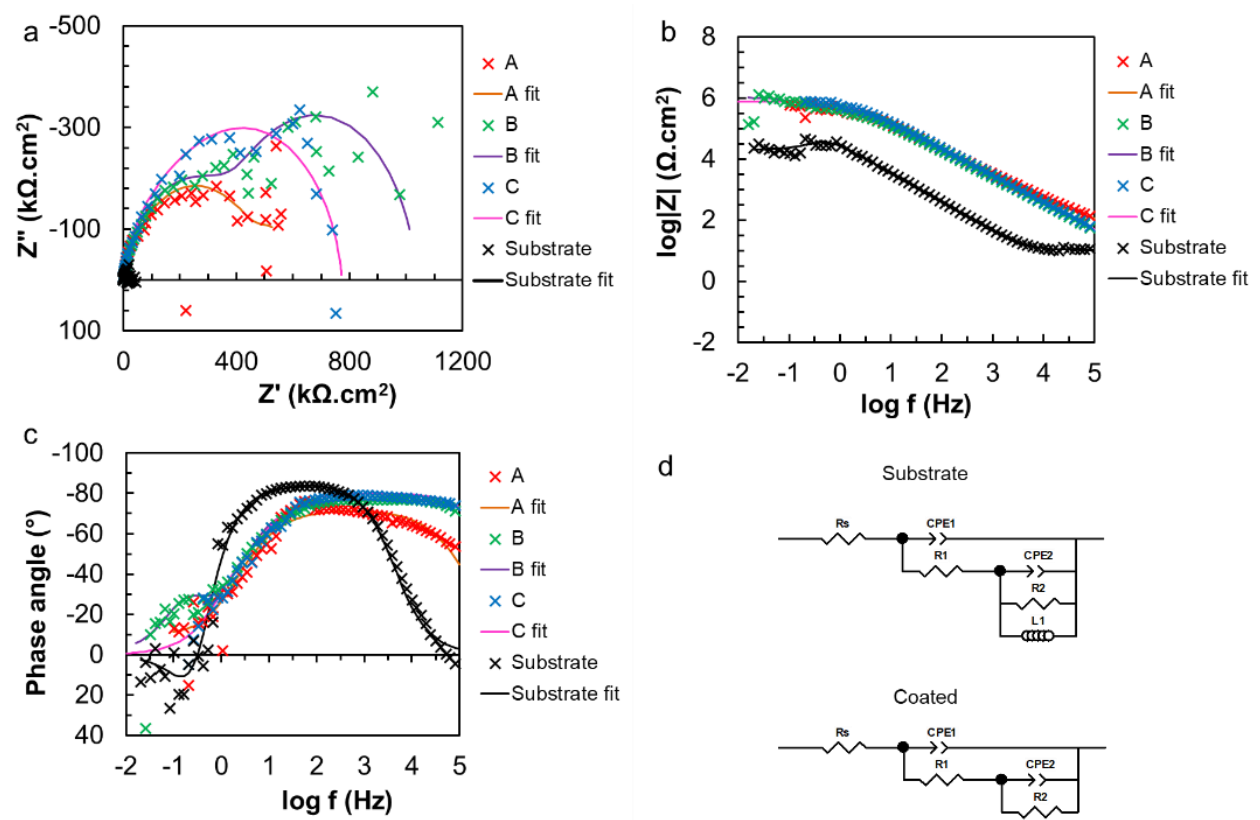

d

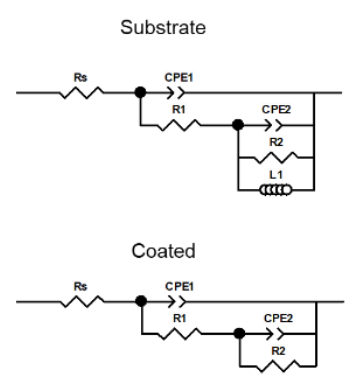

Figure 6. Electrochemical impedance spectra. 
Table 4. Fitting parameters of EIS data in Figure 6.

\begin{tabular}{ccccccccc}
\hline Specimen & $\begin{array}{c}\boldsymbol{R}_{\mathbf{s}}, \\
\mathbf{\Omega} \cdot \mathbf{c m}^{\mathbf{2}}\end{array}$ & $\begin{array}{c}\mathbf{C P E}, \\
\mathbf{\Omega}^{-\mathbf{1}} \cdot \mathbf{S}^{\boldsymbol{n}} \cdot \mathbf{c m}^{-\mathbf{2}}\end{array}$ & $\boldsymbol{n}_{\mathbf{1}}$ & $\begin{array}{c}\boldsymbol{R}_{\mathbf{1}}, \\
\mathbf{K} \boldsymbol{\omega} \cdot \mathbf{c m}^{\mathbf{2}}\end{array}$ & $\begin{array}{c}\mathbf{C P E}_{2}, \\
\mathbf{\Omega}^{-\mathbf{1}} \cdot \mathbf{S}^{\boldsymbol{n}} \cdot \mathbf{c m}^{\mathbf{2}}\end{array}$ & $\boldsymbol{n}_{\mathbf{2}}$ & $\begin{array}{c}\boldsymbol{R}_{2}, \\
\mathbf{k} \boldsymbol{\Omega} \cdot \mathbf{c m}^{\mathbf{2}}\end{array}$ & $\begin{array}{c}\boldsymbol{L}_{\mathbf{1}}, \\
\mathbf{H}\end{array}$ \\
\hline Substrate & 10.56 & $5.31 \cdot 10^{-6}$ & 0.96 & 20.72 & $7.58 \cdot 10^{-7}$ & 0.98 & 22.16 & 1947 \\
Coated-A & 10.94 & $2.66 \cdot 10^{-7}$ & 0.80 & 505.05 & $1.49 \cdot 10^{-5}$ & 0.99 & 117.84 & - \\
Coated-B & 6.14 & $1.54 \cdot 10^{-7}$ & 0.87 & 647.80 & $8.17 \cdot 10^{-7}$ & 0.99 & 119.05 & - \\
Coated-C & 3.60 & $2.34 \cdot 10^{-7}$ & 0.86 & 491.36 & $2.178 \cdot 10^{-6}$ & 0.97 & 544.90 & - \\
\hline
\end{tabular}

The variation of bath content gave an insignificant effect on the impedance modulus and phase angle, as shown in Figures $6 \mathrm{~b}$ and $6 \mathrm{c}$. However, it altered the Nyquist diagram. The diameter of the semicircle increased as going from A to B and C. The surface resistance increased from $6.22 \cdot 10^{5}$ in the A specimen to $1.42 \cdot 10^{6}$ in the B specimen and $1.03 \cdot 10^{6} \Omega \cdot \mathrm{cm}^{2}$ in the $\mathrm{C}$ specimen. The values were two orders magnitude higher than that of the substrate, $4.3 \cdot 10^{4} \Omega \cdot \mathrm{cm}^{2}$. The higher volume fraction of silicate ions in the bath resulted in the higher corrosion resistance of the functional layer. Further addition of hydroxide ions in the bath contributed to enhancing the corrosion resistance of the inner layer.

\section{Conclusion}

Non-crystalline aluminum oxide films were developed on Al substrate by PEO in a mixed alkaline electrolyte containing phosphate, carbonate, hydroxide, and silicate electrolyte. The films exhibited porous morphology but free of cracks. The oxide layer with a thickness of $\sim 2-3 \mu \mathrm{m}$ increased the specimen hardness by approximately $20 \mathrm{HV}$. Drastic improvement of the corrosion resistance was demonstrated by 10-100 times lower corrosion current density in the polarization curve and two orders magnitude enlargement of impedance spectra. Higher corrosion resistance was obtained for the film developed in the bath with higher silicate content. The combined increase of volume fraction silicate and hydroxide in the bath triggered soft sparking producing a denser film that further improved the corrosion resistance of the specimen.

\section{Acknowledgement}

This work was funded by Direktorat Inovasi dan Science Techno Park (DISTP), Universitas Indonesia, through Hibah Kompetisi Program Pendanaan Perancangan dan Pengembangan Purwarupa (P5) 2020.

\section{References}

1. A.L. Yerokhin, X. Nie, A. Leyland, A. Matthews and S.J. Dowey, Plasma electrolysis for surface engineering, Surf. Coatings Technol., 1999, 122, 73-93. doi: 10.1016/S0257$\underline{8972(99) 00441-7}$ 
2. V. Dehnavi, D.W. Shoesmith, B.L. Luan, M. Yari, X.Y. Liu and S. Rohani, Corrosion properties of plasma electrolytic oxidation coatings on an aluminium alloy - The effect of the PEO process stage, Mater. Chem. Phys., 2015, 161, 49-58. doi: 10.1016/i.matchemphys.2015.04.058

3. A. Anawati, H. Asoh and S. Ono, Degradation behavior of coatings formed by the Plasma Electrolytic Oxidation technique on AZ61 magnesium alloys containing 0, 1 And 2 Wt\% Ca, Int. J. Technol., 2018, 9. doi: 10.14716/ijtech.v9i3.712

4. V.S. Rudnev, M.V. Adigamova, I.V. Lukiyanchuk, I.A. Tkachenko and V.P. Morozova, Oxide coatings with ferromagnetic characteristics on $\mathrm{Al}, \mathrm{Ti}, \mathrm{Zr}$ and $\mathrm{Nb}$, Surf. Coatings Technol., 2020, 381, 125180. doi: 10.1016/j.surfcoat.2019.125180

5. A. Anawati, H. Asoh and S. Ono, Enhanced uniformity of apatite coating on a PEO film formed on AZ31 Mg alloy by an alkali pretreatment, Surf. Coatings Technol., 2015, 272, 182-189. doi: 10.1016/j.surfcoat.2015.04.007

6. S. Aliasghari, P. Skeldon, X. Zhou, G.B.G. Stenning, R. Valizadeh, T. Junginger and G. Burt, Incorporation of superconducting $\mathrm{MgB}_{2}$ into plasma electrolytic oxidation coatings on aluminium, Surf. Coatings Technol., 2019, 380, 125091. doi: 10.1016/j.surfcoat.2019.125091

7. E. Matykina, R. Arrabal, A. Pardo, M. Mohedano, B. Mingo, I. Rodríguez and J. González, Energy-efficient PEO process of aluminium alloys, Mater. Lett., 2014, 127, 13-16. doi: $10.1016 /$ j.matlet.2014.04.077

8. M. Kaseem, T. Hussain and Y.G. Ko, Tailored alumina coatings for corrosion inhibition considering the synergism between phosphate ions and benzotriazole, J. Alloys Compd., 2020, 822, 153566. doi: $10.1016 /$ j.jallcom.2019.153566

9. A. Anawati, H. Asoh and S. Ono, Effects of alloying element ca on the corrosion behavior and bioactivity of anodic films formed on AM60 mg alloys, Materials, 2017, 10. doi: $10.3390 / \mathrm{ma1} 0010011$

10. K. Wei, X. Wang, J. Li, Y. Qu, X. Wan, J. Du and W. Xue, In-situ Electrochemical Study of Plasma Electrolytic Oxidation Treated Zr 3 Al Based Alloy in $300{ }^{\circ} \mathrm{C} / 14 \mathrm{MPa}$ Lithium Borate Buffer Solution, Thin Solid Films, 2020, 707, 138066. doi: $\underline{10.1016 / j . t s f .2020 .138066}$

11. J. Martin, A. Nominé, V. Ntomprougkidis, S. Migot, S. Bruyère, F. Soldera, T. Belmonte and G. Henrion, Formation of a metastable nanostructured mullite during Plasma Electrolytic Oxidation of aluminium in "soft" regime condition, Mater. Des., 2019, 180, 107977. doi: 10.1016/j.matdes.2019.107977

12. J. Martin, A. Nominé, F. Brochard, J.L. Briançon, C. Noël, T. Belmonte, T. Czerwiec and G. Henrion, Delay in micro-discharges appearance during PEO of Al: Evidence of a mechanism of charge accumulation at the electrolyte/oxide interface, Appl. Surf. Sci., 2017, 410, 29-41. doi: 10.1016/j.apsusc.2017.03.088 
13. Y. Zhang, Y. Wu, D. Chen, R. Wang, D. Li, C. Guo, G. Jiang, D. Shen, S. Yu and P. Nash, Micro-structures and growth mechanisms of plasma electrolytic oxidation coatings on aluminium at different current densities, Surf. Coatings Technol., 2017, 321, 236-246. doi: 10.1016/j.surfcoat.2017.04.064

14. S.V. Gnedenkov, S.L. Sinebryukhov, V.S. Egorkin and I.E. Vyaliy, Wettability and electrochemical properties of the highly hydrophobic coatings on PEO-pretreated aluminum alloy, Surf. Coatings Technol., 2016, 307, 1241-1248. doi: 10.1016/j.surfcoat.2016.07.074

15. T.S.N.S. Narayanan, Surface pretreatment by phosphate conversion coatings - A review, Rev. Adv. Mater. Sci., 2005, 9, 130-177.

16. F. Jaspard-Mécuson, T. Czerwiec, G. Henrion, T. Belmonte, L. Dujardin, A. Viola and J. Beauvir, Tailored aluminium oxide layers by bipolar current adjustment in the Plasma Electrolytic Oxidation (PEO) process, Surf. Coatings Technol., 2007, 201, 8677-8682. doi: $\underline{\text { 10.1016/j.surfcoat.2006.09.005 }}$

17. Y.J. Guan, Y. Xia and G. Li, Growth mechanism and corrosion behavior of ceramic coatings on aluminum produced by autocontrol AC pulse PEO, Surf. Coatings Technol., 2008, 202, 4602-4612. doi: 10.1016/j.surfcoat.2008.03.031

18. M.E. Özcan, L. Özler and N. Parlak, Investigation of surface roughness of Al7075 material coated with micro-arc oxidation method, Adv. Mater. Process. Technol., 2015, 1, 67-77. doi: 10.1080/2374068X.2015.1112147

19. M. Mohedano, E. Matykina, R. Arrabal, B. Mingo and A. Pardo, PEO of pre-anodized Al-Si alloys: Corrosion properties and influence of sealings, Appl. Surf. Sci., 2015, 346, 57-67. doi: 10.1016/j.apsusc.2015.03.206

20. J.A. Curran and T.W. Clyne, Thermo-physical properties of plasma electrolytic oxide coatings on aluminium, Surf. Coatings Technol., 2005, 199, 168-176. doi: 10.1016/j.surfcoat.2004.09.037

21. S. Ono, S. Moronuki, Y. Mori, A. Koshi, J. Liao and H. Asoh, Effect of Electrolyte Concentration on the Structure and Corrosion Resistance of Anodic Films Formed on Magnesium through Plasma Electrolytic Oxidation, Electrochim. Acta, 2017, 240, 415423. doi: $10.1016 /$ j.electacta.2017.04.110

22. J.M. Wheeler, J.A. Curran and S. Shrestha, Microstructure and multi-scale mechanical behavior of hard anodized and plasma electrolytic oxidation (PEO) coatings on aluminum alloy 5052, Surf. Coatings Technol., 2012, 207, 480-488. doi: $\underline{10.1016 / \mathrm{j} . \text { surfcoat.2012.07.056 }}$ 